\title{
Dissemination Matters: Influences of Dissemination Activities on User Types in an Online Educational Community
}

\author{
Min Yuan ${ }^{1}$, Mimi Recker ${ }^{1}$ \\ ${ }^{1}$ Utah State University
}

\begin{abstract}
Emerging online educational communities provide spaces for teachers to find resources, create instructional activities, and share these activities with others. Within these online communities, individual users' activities may vary widely, and thus different user types can be identified. In addition, users' patterns of activities in online communities are dynamic, and further can be affected by dissemination activities. Through analyzing usage analytics in an online teacher community called the Instructional Architect, this study explores the influences of dissemination activities on the usage patterns of different user types. Results show that dissemination activities can play an important role in encouraging users' active participation, while the absence of dissemination activities can further increase participation inequality.
\end{abstract}

Keywords - Educational technology, Learning systems, Online Communities, Pattern analysis

\section{INTRODUCTION}

$\mathrm{T}$ EACHERS increasingly rely on the Internet to find online learning resources, create instructional activities using these resources, and then share these with others [1]-[4]. To help teachers in these tasks, several web-based tools, such as the Instructional Architect, the Curriculum Customization Service, and Tapped In, have been developed [5]-[7]. These tools are designed to help teachers' knowledge building processes, as well as to help support the development of online educational communities [8].

In an online educational community, a virtual space is provided for teachers and learners to seek information, ask questions, and interact with one and another [9]. In general, an online educational community contains the following four elements: people who create content and connect with each other, computer systems that mediate people's activities, policies that guide people's activities, and purposes that provide reasons and motivations for people to participate [10]. People participating in an online educational community typically have shared purposes, but their actual activities in the community can vary widely. For example, some teachers may actively collect resources and design instructional activities using these resources, some may willingly share their resources and teaching activities with other users, while others may simply engage in viewing other users' activities [11], [12].

As people engage in these different activities, they can be categorized into different user types. At a high level, two main categories of users have been identified in online communities: lurkers, who take on more non-participatory roles and principally view other members' activities and products; and contributors, who take on more active roles, create new content, and share with the community [13], [14]. Prior research has also detected that the lurker-contributor ratio in communities is often skewed, with substantially more lurkers than contributors [1], [14], [15], [16].

Further, patterns of activity over time in online educational communities are dynamic, resulting in different developmental paths [17]. For example, over time, one online community may thrive and grow with more user activity, while another may shrink (or even die) with fewer users and less participation [18]. Additionally, as time passes, some lurkers may follow a trajectory toward becoming contributors in a community [19].

However, despite prior research on characterizing user typologies in online educational communities, less work has focused on understanding user activity patterns, the evolution of patterns over time, and the resulting dynamics of online educational communities. As such, in this article, we report results from applying techniques from the emerging field of learning analytics to analyze usage patterns in an online educational community for teachers, called the Instructional Architect (IA.usu.edu). Understanding the evolution of user activities and the dynamics of a community is complex, as the analysis revolves around mining the massive amounts of data automatically generated by the community [7], [22]. Techniques from learning analytics offer approaches for analyzing these kinds of data, such as comparing users' number of logins and visit duration, analyzing user-generated content, and examining the relationships between users [23], [24]. Outcomes of such research can provide suggestions for dissemination activities that can promote particular users' activities in order to enhance the development and sustainability of online communities [20], [21].

In particular, this article reports results of longitudinal analyses of usage data automatically collected by the IA over two full school years. During the first school-year period 
(2009-10), the development team conducted extensive dissemination activities; however, these had ceased by the second school-year period (2012-13). In this way, we explored the influences of dissemination activities on different IA user types, and whether these typologies changed after dissemination activities ended. By comparing the analytics of different user types during and after dissemination, this study identified which user types and what kind of activities were most affected when dissemination activities ended, thus providing insights on the sustainability of online communities.

\section{THEORETICAL CONTEXT}

\section{A. Online Educational Communities}

Online educational communities have become an important part of teachers' lives, in that they can help teachers' seek instructional resources and interact with other teachers [13], [25]. Like any community, these online educational communities have different life cycles.

Researchers have provided a variety of definitions and descriptions of these life cycles. For example, [20] defined three stages in the life cycle: starting the online community, encouraging early online interaction, and moving to a selfsustaining community. [18] divided the life cycle into five stages: inception, creation, growth, maturity, and death.

Although the definitions are different, researchers have identified similar development trajectories in the evolution of online communities. For example, in the early stage of an online community, the technological components are developed and groups of users with similar purposes and needs begin to create content and/or interact with each other. At maturity or the self-sustaining stage, the community may have a large number of members and a large repository of content [18].

In addition, in analyzing the life cycles of communities, researchers have also focused on the role that dissemination plays in the development of communities. They noted that dissemination activities are important in encouraging users' early participation and interaction, in maintaining their interests over time, and in supporting the sustainability of communities [20], [18], [26].

In this vein, researchers have identified factors that can influence the development and sustainability of online community. For example, [27] listed two factors: the creation of content and the interaction between users. [9] analyzed two factors that appeared to determine the success of online communities: usability (how people can access, create, and use content), and sociability (how users can interact).

\section{B. Users in Online Educational Communities}

Research has also focused on identifying different user typologies based on users' participation practices in an online community. For example, [15] categorized users of the Instructional Architect based on their activity patterns using a probabilistic clustering algorithm. Results revealed three types of user groups, where each group had characteristic patterns in terms of its frequency in creating, viewing, and sharing content. Similarly, [16] investigated usage patterns in the Curriculum Customization Service by analyzing users' clickstream data. They found that some user types were characterized by viewing many interactive resources and shared resources, while other types were spending more time on viewing instructional materials and assessments.

By reviewing user patterns across several different online communities, [14] proposed the "90-9-1" rule. This rule divides users into three groups: 1) approximately $90 \%$ of the users are lurkers, who view other users' resources and products but do not contribute; 2) $9 \%$ of the users are intermittent contributors; and 3) $1 \%$ of the users are heavy contributors, who participate heavily and create most of the content in the community.

This "participation inequality" rate has been observed in several online communities. For example, [28] investigated the distribution of contributions made by authors in Wikipedia, and found that less than $10 \%$ of the total number of authors created more than $90 \%$ of the content. In analyzing usergenerated content in nine popular websites (e.g., Amazon book review, Merlot.org, Slideshare.net), [29] found that the distribution of user-generated content similarly followed a "long-tail" distribution, thus providing further evidence of participation inequality.

This "participation inequality" phenomenon results in a skewed lurker-contributor ratio, as well as the "free riding" problem. In this phenomenon, users benefit from other users' activities without contributing anything in return [30]. If many users become "free riders" (or lurkers) in a community, participation and the number of resources created in the community will grow slowly, which may in turn negatively affect users' interest as well as the overall sustainability of the community [31].

To further examine participation inequality and the potential free riding problem, researchers have studied why lurkers may behave this way. Reasons for lurking include a desire for users to get to know the norms of a community before becoming contributors, a lack of familiarity with the community, a lack of reasons for contributing content, and technology barriers [11], [13]. In addition, by comparing lurkers and non-lurkers' activities, researchers have found that non-lurkers tend to have a desire for a greater variety of activities, such as getting answers to questions, participating in conversations, or offering expertise [11].

It is also important to note that users' activities in the communities often change over time. For example, lurkers can begin to create and share their products once they become more familiar with the functions of the online community and build trust with other users. Non-lurkers can become lurkers as they gradually lose interest or their needs are satisfied [18]. Thus, understanding how the activities of different types of users evolve over time, especially in response to changes in support or dissemination activities within the community, are needed. 


\section{TECHNOLOGICAL CONTEXT}

The technological context for this study is the Instructional Architect (IA). The IA is a free, web-based tool that was first launched in 2001. Using iterative design approaches, the tool was improved several times and development stabilized in 2005, before the data were collected for the present article.

The IA enables teachers to use online educational resources to create, publish, and share instructional activities (called IA projects) within the IA online community [5], [32]. Figure 1 shows an IA project created by a teacher. This IA project, on the topic of the "Underground Railroad", provides text, maps, and links to supporting resources.

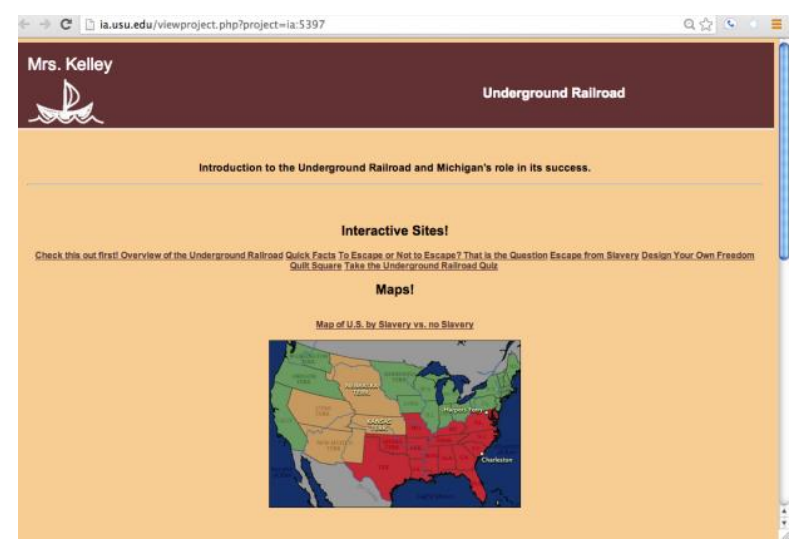

Fig. 1. A screenshot of a teacher-created IA project

Within the IA online educational community, users can engage in many different activities. Without logging in, any user can browse IA projects created and shared by other IA users. After logging in, a user can also collect online resources in his/hew own personal repository of online resources by using the 'My Resources' area of the IA to search for and save online resources from existing content repositories (e.g., the NSDL.org), or online content including web pages, pdf documents, or other public IA projects.

In the 'My Projects' area, teachers can create IA projects using online resources they have collected and annotate them with text. An IA project (a webpage) is then generated, which can then be used in a classroom activity. Finally, teachers can share IA projects by making them public, so that other users can easily view and copy them.

Since 2005, the IA has approximately 7,900 registered users, who have gathered over 75,600 online resources and created over 17,300 IA projects. Since August 2006, public IA projects have been viewed over 2.5 million times.

\section{RESEARCH DESIGN}

\section{A. Research Design}

This study analyzed the usage log files automatically collected by the IA in order to examine the evolution of the activity patterns of different user types. Two different time periods were examined: one in which dissemination activities were ongoing, and the other in which they had ended.
Since the launch of the IA, developers and researchers have taken many approaches for disseminating the tool to teachers. These included advertising online, offering teacher professional development workshops, and presenting at conferences. [32]. For example, between 2007 and 2011, a series of teacher workshops were conducted in several U.S. states, including South Dakota, Illinois, New York, and Utah. The workshops familiarized teachers with the IA, showed them how to design IA projects, and encouraged them to integrate these IA projects in their teaching.

In addition, members of the development team presented about the IA at several conferences, including the International Conference on Educational Data Mining, Joint Conference on Digital Library, the Annual Meeting of the Association for Educational Communications Technology, and the Annual Meeting of the American Education Research Association [33]-[36], as well as local, teacher-oriented conferences.

To examine the influence of dissemination activities on IA users types, this study compared the activities of different IA user types during two time periods: 1) the "active dissemination" period (9 months between 09/01/2009 $05 / 31 / 2010$ ), in which developers engaged in active dissemination activities, and 2) the "no dissemination" period (9 months between 09/01/2012 - 05/31/2013) in which dissemination activities had ended. Note that the nine-month period corresponds to the school year of U.S. teachers, our target users. It is also noteworthy that the activities we analyzed are IA users' naturally occurring behaviors, and not those of users specifically recruited to participate in a research study.

Specifically, this study had two research purposes: examining 1) how the IA community evolved and changed during and after dissemination activities, and 2) more specifically, how the activities of particular subsets of IA users also changed after dissemination activities ended. To align with these purposes, different user groups and data sources were used to address two research questions (see Table 1):

1. How did the activities of IA visitors change between the "active dissemination" period and the "no dissemination" period?

2.How did the activities of lurkers and active contributors change between the "active dissemination" period and the "no dissemination" period?

Usage activity in the IA is automatically collected by two complementary data sources: Google Analytics (GA) and the relational database powering the IA site (IADB). As a Google service, GA records the activities of all users in the IA website (which we call IA visitors). In particular, GA tracks visitors to the IA website, regardless of whether they have an account. In this analysis, we used seven metrics collected by GA (see Table 2) to analyze the activities of IA visitors. 
TABLE 1

RESEARCH QUESTIONS AND DATA SOURCES

\begin{tabular}{lll}
\hline $\begin{array}{c}\text { Research } \\
\text { Questions }\end{array}$ & \multicolumn{1}{c}{ User Group Analyzed } & \multicolumn{1}{c}{$\begin{array}{c}\text { Data } \\
\text { Sources }\end{array}$} \\
\hline RQ1 & All visitors to the IA site & $\begin{array}{l}\text { Google } \\
\text { Analytics }\end{array}$ \\
RQ2 & $\begin{array}{l}\text { Users who created an IA account, in two } \\
\text { groups: lurkers (did not create IA } \\
\text { project) and active contributors (created } \\
\text { IA projects) }\end{array}$ & IA database \\
& & \\
\hline \hline
\end{tabular}

\section{B. Data Sources}

TABLE 2

METRICS DESCRIBING ACTIVITIES OF IA VISITORS USING GOOGLE ANALYTICS

\begin{tabular}{|c|c|}
\hline Metric & Description \\
\hline \# of visits & $\begin{array}{l}\text { Number of visits to the website within a date range. A } \\
\text { visit encompasses a set of interactions within the website } \\
\text { (e.g. multiple page views). }\end{array}$ \\
\hline \# of new visits & Estimated number of the first-time visits. \\
\hline $\begin{array}{l}\text { \# of unique } \\
\text { visitors }\end{array}$ & $\begin{array}{l}\text { Number of unduplicated (counted only once) visitors to } \\
\text { the website within a date range. }\end{array}$ \\
\hline $\begin{array}{l}\text { \# of page } \\
\text { views }\end{array}$ & $\begin{array}{l}\text { Total number of pages viewed, including repeated views } \\
\text { of a single page. }\end{array}$ \\
\hline $\begin{array}{l}\text { Pageviews per } \\
\text { visit }\end{array}$ & $\begin{array}{l}\text { The ratio of total number of page viewed to number of } \\
\text { visits. }\end{array}$ \\
\hline $\begin{array}{l}\text { Average visit } \\
\text { duration }\end{array}$ & Average duration of a visit measured in seconds. \\
\hline Bounce rate & $\begin{array}{l}\text { Percentage of single-page visits (users who visit only one } \\
\text { page of the website and then leave) }\end{array}$ \\
\hline
\end{tabular}

Note. Descriptions provided by Google Analytics.

TABLE 3

METRICS DESCRIBING ACTIVITIES OF USERS USING THE IADB

\begin{tabular}{ll}
\hline \hline \multicolumn{1}{c}{ Metric } & \multicolumn{1}{c}{ Description } \\
\hline \# of logins & $\begin{array}{l}\text { Number of times users log into the IA website } \\
\text { within a date range }\end{array}$ \\
$\begin{array}{l}\text { \# of IA projects } \\
\text { created }\end{array}$ & $\begin{array}{l}\text { Number of IA projects created by users within a } \\
\text { date range. }\end{array}$ \\
$\begin{array}{l}\text { \# of IA public projects } \\
\text { created }\end{array}$ & $\begin{array}{l}\text { Number of IA projects published within a date } \\
\text { range. }\end{array}$ \\
$\begin{array}{l}\text { \# of IA projects } \\
\text { copied }\end{array}$ & $\begin{array}{l}\text { Number of IA projects copied from others within } \\
\text { a of online resources } \\
\text { used }\end{array}$ \\
\hline \hline
\end{tabular}

In contrast, the IADB records the activities of individual users who have registered for an account in the IA website. Using this data, we defined three categories of IA users for a particular time period: lurkers, who did not create IA projects; contributors, who created but did not share IA projects; and active contributors, who created and shared IA projects. In this analysis, we focused on two user types - lurkers and active contributors, and analyzed five metrics collected by the IADB capturing the activities of these users (see Table 3).

Also note that based on users' activities collected by IADB and GA, we assume that lurkers and active contributors are primarily teachers, while IA visitors come for the general Internet user base.

\section{V.RESULTS}

\section{A. RQ1: Influence of Dissemination Activities on IA Visitors}

Using the analytics from GA, Figures 2-8 compare the activities of IA visitors during the "active dissemination" and "no dissemination" periods (averaged monthly over the time period). Table 4 compares the activities of IA visitors averaged daily over these two time periods. The comparisons are made in terms of key GA analytics: the number of visits, new visits, unique visitors, pageviews, and pageviews per visit, as well as visit duration and bounce rate.

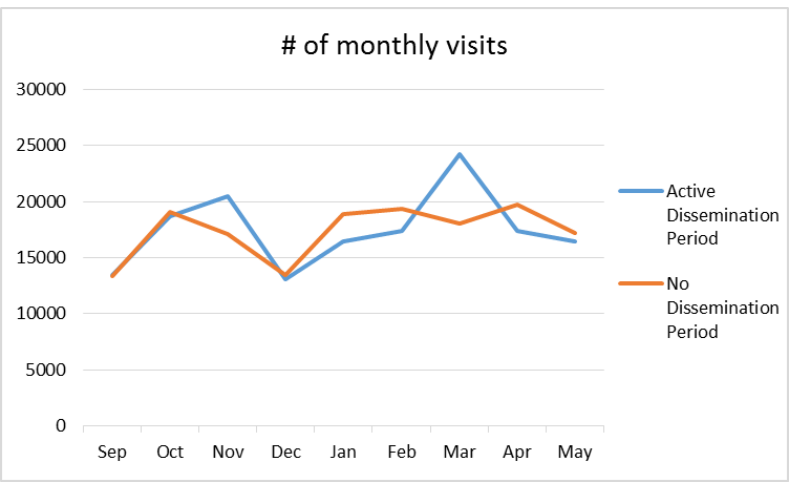

Fig. 2. Number of visits

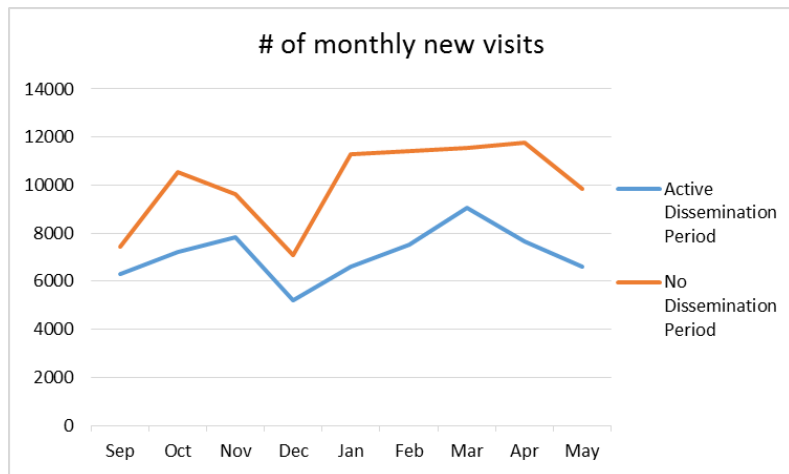

Fig. 3. Number of new visits

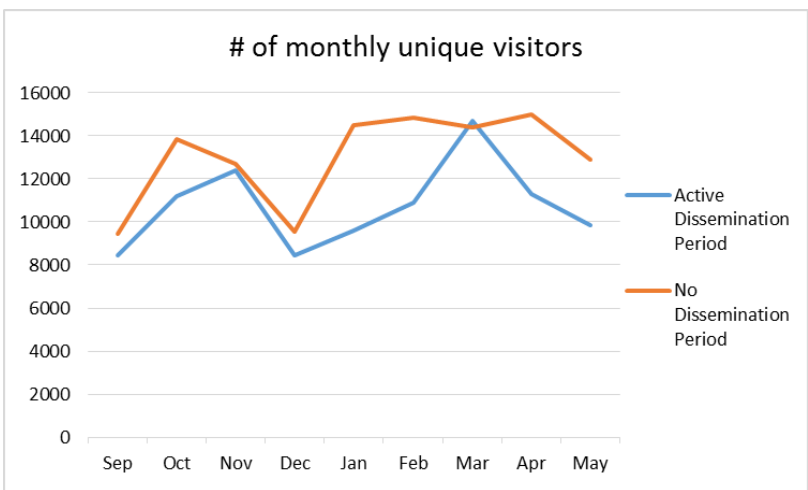

Fig. 4. Number of unique visitors 


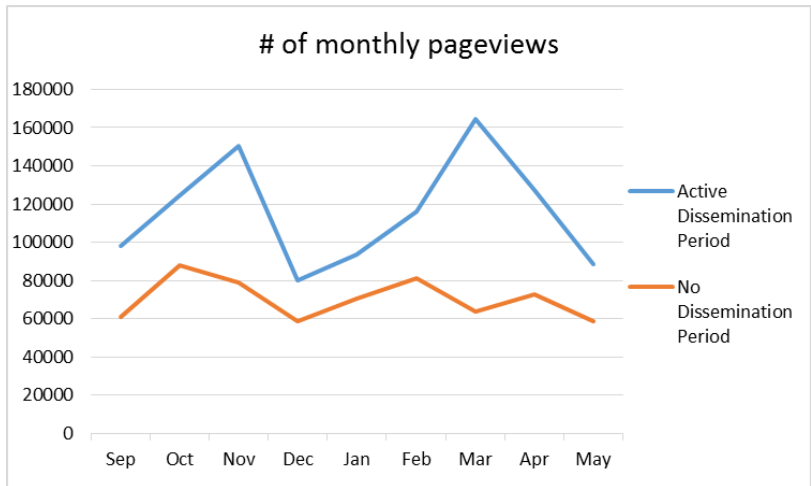

Fig. 5. Number of pageviews

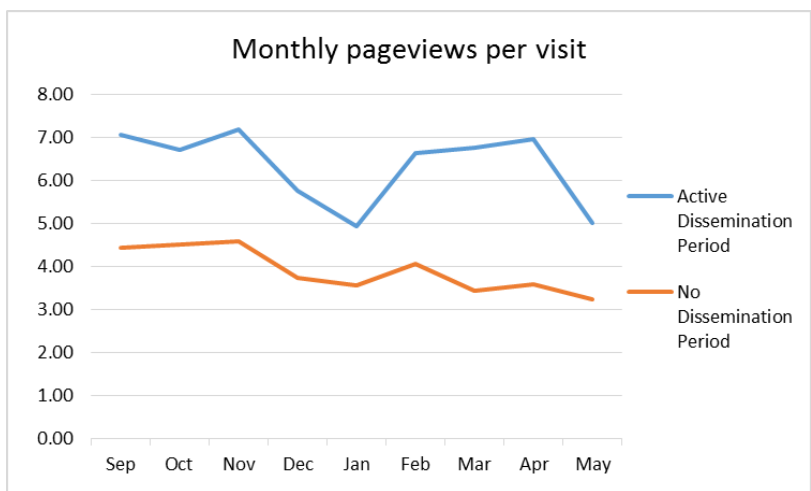

Fig. 6. Number of pageviews per visit

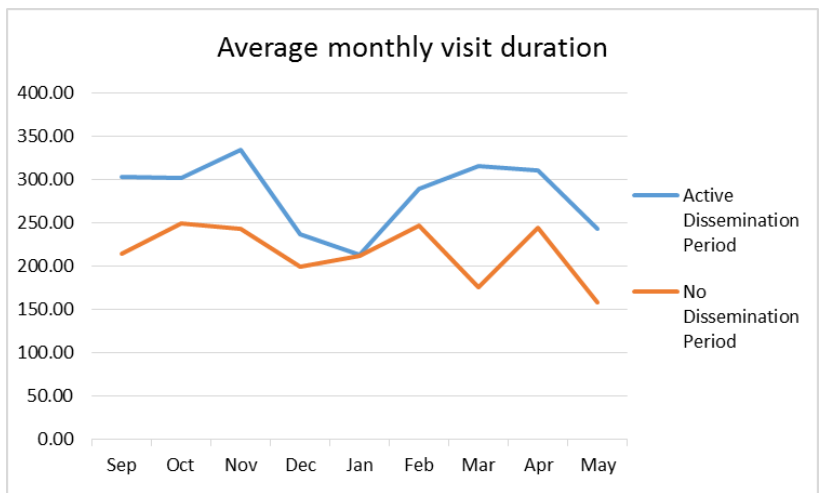

Fig. 7. Visit duration (measured in seconds)

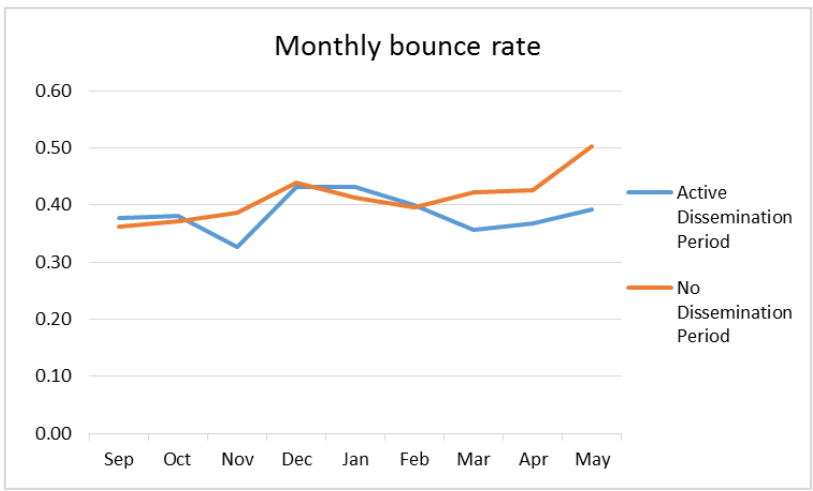

Fig. 8. Bounce rate

Due to non-normal distributions of the data, the MannWhitney test was used to compare whether visitors' activities between these two time periods were significantly different. As suggested by Figure 2, the overall number of visits did not differ significantly between these two time periods $(\mathrm{U}=$ $37129.50, p=.94)$. This suggests that dissemination activities had little effect on the overall number of visitors.

However, the number of new visits, the number of unique visitors, and the bounce rate all increased significantly during the subsequent "no dissemination" period ( $\mathrm{U}=24773.50, p<$ $.001 ; \mathrm{U}=29879.00, p<.001 ; \mathrm{U}=29916.00, p<.001)$. In contrast, the number of pageviews and pageviews per visit, as well as average visit duration decreased significantly $(\mathrm{U}=$ 26917.50, $p<.001 ; \mathrm{U}=12897.50, p<.001 ; \mathrm{U}=25048.00, p$ $<.001)$. Taken together, these results suggest that while the overall number of visits stayed even between periods, the "active dissemination" period was characterized by more engaged visitors.

Note that one task of the IA is to help users to find useful online resources, and thus many IA projects contain links that lead users to resources outside the IA website (therefore inflating the bounce rate). It is plausible that the subsequent, "no dissemination" period was populated by more savvy users, who were quickly able to find desired resources. This would help explain the overall similar number of visits, coupled with decreased number of pageviews, visit duration, and higher bounce rate during this period.

TABLE 4

COMPARISON OF IA visitors’' ACTIVITIES BETWEEN Two Time PERIOdS

\begin{tabular}{|c|c|c|c|c|c|c|}
\hline & \multicolumn{3}{|c|}{ "Active dissemination } & \multicolumn{3}{|c|}{ No dissemination } \\
\hline & Mean & Median & SD & Mean & Median & $\mathrm{SD}$ \\
\hline \# of visits & 577.70 & 641.00 & 364.73 & 572.48 & 607.00 & 338.52 \\
\hline $\begin{array}{l}\text { \# of new } \\
\text { visits * }\end{array}$ & 234.38 & 233.00 & 116.34 & 331.55 & 331.00 & 177.89 \\
\hline $\begin{array}{l}\text { \# of unique } \\
\text { visitors * }\end{array}$ & 355.03 & 371.00 & 193.73 & 429.33 & 442.00 & 236.35 \\
\hline $\begin{array}{l}\text { \# of } \\
\text { pageviews* }\end{array}$ & 3821.04 & 3351.00 & 2937.54 & 2321.77 & 2345.00 & 1569.38 \\
\hline $\begin{array}{l}\text { Pageviews } \\
\text { per visit * }\end{array}$ & 6.32 & 5.88 & 2.60 & 3.90 & 3.72 & 1.19 \\
\hline $\begin{array}{l}\text { Average } \\
\text { visit } \\
\text { duration } \\
\text { (seconds) * }\end{array}$ & 282.39 & 265.51 & 125.30 & 215.04 & 206.74 & 98.20 \\
\hline $\begin{array}{l}\text { Bounce rate } \\
*\end{array}$ & .39 & .38 & .09 & .41 & .42 & .08 \\
\hline
\end{tabular}

* Difference between the two time periods is significant (Mann-Whitney test; $\mathrm{p}<.05$ )

\section{B. RQ2: Influence of Dissemination Activities on Lurkers and Active Contributors}

Table 5 compares the number of lurkers and active contributors between the two time periods, using analytics from the IADB. Recall that lurkers are defined as users who created an IA account but did not create any IA projects during the given time period. Active contributors are defined as users who created and shared IA projects during the given time period.

As shown in Table 5, after the dissemination activities ended, the number of lurkers increased while the number of 
active contributors decreased. Note that the number of active contributors in the "active dissemination" period was about six times greater than during the "no dissemination" period, suggesting that dissemination activities may have helped encourage users' active participation. The large drop of active contributors during the "no dissemination" period may exacerbate the free riding problems, as only a very small portion of users contributed IA projects during this period. In addition, a large increase can be seen in the lurker-active contributor ratio. This suggests that ceasing dissemination activities can lead to a more skewed lurker-active contributor ratio and thus aggravate participation inequality.

TABLE 5

THE NUMBER OF USERS IN EACH CATEGORY

\begin{tabular}{lrr}
\hline \hline & Active dissemination & No dissemination \\
\hline \# of lurkers & 3908 & 6201 \\
\# of active contributors & 547 & 92 \\
$\begin{array}{l}\text { Lurker-active contributor } \\
\text { ratio }\end{array}$ & $7: 1$ & $66: 1$ \\
\hline \hline
\end{tabular}

\section{Evolution of Lurkers}

Table 6 compares lurkers' mean number of logins between the two time periods, which significantly decreased after dissemination activities ceased $(\mathrm{U}=1.20, p<.001)$. This suggests that during the subsequent "no dissemination" period, lurkers were less likely to log in, and thus less likely to make use of features in the IA community.

As can also be seen, the number logins for lurkers was very low. Note that one function of the IA community is to facilitate teachers' browsing existing IA project, and login is not required to view IA projects. As such, the low number of logins does not necessarily mean that lurkers viewed fewer projects or became inactive - they may simply have chosen to view IA projects without logging in. Unfortunately, our analytics do not enable us to track visitors who do not log in at the individual user level.

\section{Evolution of Active Contributors}

Compared to the "active dissemination" period, all five metrics for active contributors at the aggregated level declined during the "no dissemination" period. As can be seen from Table 7, they had fewer logins, created fewer IA projects, shared fewer IA projects, copied fewer IA projects from other users, and used fewer online resources in their IA projects.

However, a closer examination of active contributors' individual activities revealed a different picture. As shown in Table 8, during the "no dissemination" period, active contributors on average had significantly fewer logins $(\mathrm{U}=$ $21531.00, \mathrm{p}<.05$ ), and used significantly fewer online resources $(\mathrm{U}=21269.00, \mathrm{p}<.05)$. However, each active contributor on average created significantly more IA projects, shared significantly more of these, but copied significantly less $(\mathrm{U}=18826.00, \mathrm{p}<.001 ; \mathrm{U}=16673.50, \mathrm{p}<.001 ; \mathrm{U}=$ 20974.50, $\mathrm{p}<.001)$.
TABLE 6

COMPARISON OF LURKers' MeAN \# OF LOGINS BETweEn Two Time Periods

\begin{tabular}{lcccccc}
\hline \hline & \multicolumn{3}{c}{ Active dissemination } & \multicolumn{3}{c}{ No dissemination } \\
\hline & Mean & Median & SD & Mean & Median & SD \\
\hline \# of logins & .09 & 0 & 1.01 & .04 & 0 & .96 \\
\hline \hline
\end{tabular}

TABLE 7

COMPARISON OF ACTIVE CONTRIBUTORS' ACTIVITIES AT AGGREGATE LEVEL BETWEEN TWO TIME PERIODS

\begin{tabular}{lcc}
\hline \hline & $\begin{array}{c}\text { Active } \\
\text { dissemination }\end{array}$ & $\begin{array}{c}\text { No } \\
\text { dissemination }\end{array}$ \\
\hline \# of logins & 3440 & 474 \\
\# of IA projects created & 1890 & 399 \\
$\begin{array}{l}\text { \# (\%) of IA public projects } \\
\text { created }\end{array}$ & $1194(63 \%)$ & $310(77 \%)$ \\
\# (\%) of IA projects copied & $422(22 \%)$ & $18(4 \%)$ \\
\# of online resources used & 6509 & 1017 \\
\hline \hline
\end{tabular}

TABLE 8

COMPARISON OF ACTIVE CONTRIBUTORS' ACTIVITIES AT INDIVIDUAL LEVEL BETWEen Two TIME PERIODS

\begin{tabular}{|c|c|c|c|c|c|c|}
\hline & \multicolumn{3}{|c|}{ Active dissemination } & \multicolumn{3}{|c|}{ No dissemination } \\
\hline & Mean & Median & SD & Mean & Median & SD \\
\hline$\#$ of logins * & 6.29 & 4.00 & 7.60 & 5.15 & 3.00 & 6.59 \\
\hline $\begin{array}{l}\# \text { of IA projects } \\
\text { created * }\end{array}$ & 3.46 & 2.00 & 3.82 & 4.34 & 5.00 & 2.91 \\
\hline $\begin{array}{l}\# \text { of IA public } \\
\text { projects created } *\end{array}$ & 2.18 & 1.00 & 2.92 & 3.37 & 2.50 & 2.60 \\
\hline $\begin{array}{l}\# \text { of IA projects } \\
\text { copied * }\end{array}$ & .77 & 0 & 1.79 & .20 & 0 & .47 \\
\hline $\begin{array}{l}\text { \# of online resources } \\
\text { used * }\end{array}$ & 11.90 & 8.00 & 16.59 & 11.05 & 12.00 & 8.63 \\
\hline
\end{tabular}

* Difference between the two time periods is significant (Mann-Whitney test; $\mathrm{p}<.05)$

In sum, after the dissemination activities ended, the number of active contributors significantly declined, with a corresponding decline in the number of IA projects created, shared, and copied, and resources used. However, the remaining active contributors on average increased their levels of engagement in the community by creating and sharing significantly more IA projects.

\section{DISCUSSION AND CONCLUSION}

This article described a study that examined the analytics automatically collected by usage logs in order to compare user activity patterns in an online educational community during and after dissemination activities. This study first provided an overall view of the community by exploring changes in $I A$ visitors' activities during the two time periods. Second, this study focused on two types of IA users - lurkers and active contributors - and compared the dynamics of their activities in the community during the two time periods.

In comparing activities of IA visitors between the "active 
dissemination" and "no dissemination" period, we noted that the number of new visits and the number of unique visitors increased. This suggests that even though dissemination activities ended, the IA website attracted a growing number of new visitors and thus increased its audience size. This also suggests that users continue to find the IA online community useful for their tasks.

However, during the subsequent "no dissemination" period, the number of pageviews, pageviews per visit, and average visit duration decreased -- IA visitors viewed fewer IA projects and spent less time per visit. This could suggest that IA users are becoming more efficient in discovering information they desire. Alternatively, it could indicate that many IA projects were not visited, which makes content discovery a problem. Thus, the IA developers may consider user interface enhancements to recommend IA projects to users, so as to increase the number and variety of IA projects viewed by users [24].

We then compared users who have created an account in the IA in terms of two types of users: lurkers and active contributors. During the subsequent "no dissemination" period, the lurkers' number of logins decreased significantly, suggesting that they were less likely to consider themselves as members of IA community [11].

In comparing active contributors during the two time periods, we found that the number of active contributors dropped considerably during the "no dissemination" period. This resulted in an overall decrease in the amount of new content created in the community. However, on average, the remaining active contributors were much more engaged: they created more IA projects, and shared a higher percent of their IA projects. Thus while participation inequality increased after dissemination, the remaining active contributors were, plainly stated, more engaged contributors.

In sum, dissemination activities appear to play an important role in encouraging users' active participation in the IA community. With the absence of dissemination, while the overall number of visitors did not decrease, the lurker-active contributor ratio increased in the IA community. That is, participation inequality increased. Yet, those that remained active were more engaged contributors. Thus, at least for the IA community, it appears that dissemination is important in decreasing participation inequality and in increasing lurkers' sense of community, thereby contributing to the sustainability of the online community.

In conclusion, this study contributes to our understanding of how dissemination activities can influence the evolution of different user types in an online community. In addition, it shows how different kinds of analytics data can be used to help understand the dynamics of different user types. This, in turn, can help inform strategies for attracting new users, increasing the loyalty of existing users, and improving existing communities [12]. However, as this study only focused on one online educational community and contrasted user analytics during two relatively short time periods ( 9 months each), future research is needed.

\section{ACKNOWLEDGMENT}

The authors would like to thank the many users of the Instructional Architect. This material is based upon work supported by the National Science Foundation under Grant No. 0937630, and Utah State University. Any opinions, findings, and conclusions or recommendations expressed in this material are those of the author(s) and do not necessarily reflect the views of the National Science Foundation. Portions of this research were previously presented at the $11^{\text {th }}$ International Conference of the Learning Sciences (ICLS) in Boulder, Colorado, USA.

\section{REFERENCES}

[1] S. Abramovich, C.D. Schunn, and R. J. Correnti, "The role of evaluative metadata in an online teacher resource exchange," Educational Technology Research and Development, vol. 61, no. 6, pp. 863-883, 2013.

[2] D. E. Atkins, J. S. Brown, and A. L. Hammond (2007). A review of the open educational resources (OER) movement: Achievements, challenges, and new opportunities. Available: http://www.hewlett.org/Programs/Education/OER/OpenContent/Hewlett + OER+Report.htm

[3] C. L. Borgman, H. Abelson, L. Dirks, R. Johnson, K. R. Koedinger, M.C. Linn, C. A. Lynch, D. G. Oblinger, R. D. Pea, K. Salen, M. S. Smith, A. Szalay, "Fostering learning in the networked world: The cyberlearning opportunity and challenge, a 21 st century agenda for the National Science Foundation". Report of the NSF Task Force on Cyberlearning. Virginia, US: NSF, 2008.

[4] M. Recker, A. Walker, S. Giersch, X. Mao, S. Halioris, B. Palmer, ... and M. B. Robertshaw, "A study of teachers' use of online learning resources to design classroom activities," New Review of Hypermedia and Multimedia, vol. 13, no. 2, pp. 117-134, 2007.

[5] M. Recker, "Perspectives on teachers as digital library users: Consumers, contributors, and designers," D-Lib Magazine, vol. 12, no. 9, $2006 . \quad$ Available: http://www.dlib.org/dlib/september06/recker/09recker.html

[6] T. Sumner and CCS Team, "Customizing science instruction with educational digital libraries," In 2010 Proceedings of the 10th annual joint conference on Digital libraries, pp. 353-356.

[7] M. Schlager, U. Farooq, J. Fusco, P. Schank, P., and N. Dwyer, "Analyzing online social networking in professional learning communities: Cyber networks require cyber-research tools". Journal of Teacher Education, vol. 60, no. 1, pp. 86-100, 2009.

[8] R. J. Windle, H. Wharrad, D. McCormick, H. Laverty, and M. Taylor, (2010). Sharing and reuse in OER: experiences gained from open reusable learning objects in health. Journal of Interactive Media in Education [online]. $2010 \quad$ (01). Available: http://jime.open.ac.uk/jime/article/viewArticle/2010-4/html

[9] J. Preece, "Sociability and usability in online communities: Determining and measuring success," Behaviour \& Information Technology, vol. 20, no. 5, pp. 347-356, 2001.

[10] C. L. Hsu, and H. P. Lu, "Consumer behavior in online game communities: A motivational factor perspective," Computers in Human Behavior, vol. 23, no. 3, pp. 1642-1659, 2007.

[11] B. Nonnecke, D. Andrews, and J. Preece, "Non-public and public online community participation: Needs, attitudes and behavior," Electronic Commerce Research, vol. 6, no. 1, pp. 7-20, 2006.

[12] K. Panciera, R. Priedhorsky, T. Erickson, and L. Terveen, "Lurking? cyclopaths?: a quantitative lifecycle analysis of user behavior in a geowiki," In 2010 Proceedings of the SIGCHI Conference on Human Factors in Computing Systems, pp. 1917-1926.

[13] J. Bishop, "Increasing participation in online communities: A framework for human-computer interaction", Computers in human behavior, vol. 23, no. 4, pp.1881-1893, 2007. 
[14] J. Nielsen, (2006). Participation Inequality: Lurkers vs. Contributors in Internet Communities [online]. Available: http://www.nngroup.com/articles/participation-inequality/.

[15] B. Xu and M. Recker, "Teaching Analytics: A Clustering and Triangulation Study of Digital Library User Data", Educational Technology \& Society Journal, vol. 15, no. 3, pp. 103-115, 2012.

[16] K. E. Maull, M. G. Saldivar, and T. Sumner, "Online Curriculum Planning Behavior of Teachers". In 2010 proceedings of EDM, pp. 121130 .

[17] D. Maloney-Krichmar and J. Preece, "A multilevel analysis of sociability, usability, and community dynamics in an online health community," ACM Transactions on Computer-Human Interaction (TOCHI), vol. 12, no. 2, pp. 201-232, 2005.

[18] A. Iriberri and G. Leroy, "A life-cycle perspective on online community success," ACM Computing Surveys (CSUR), vol. 41, no. 2, pp. 11-40, 2009.

[19] B. Nonnecke and J. Preece, Shedding light on lurkers in online communities, Ethnographic Studies in Real and Virtual Environments: Inhabited Information Spaces and Connected Communities, Edinburgh, 1999, pp. 123-128.

[20] D. Andrews, J. Preece, and M. Turoff, M, "A conceptual framework for demographic groups resistant to online community interaction," in 2001 proceedings of the 34th Annual Hawaii International Conference on system sciences, pp. 10-20.

[21] T. Elias, "Learning analytics: Definitions, processes and potential. Learning," Learning, vol. 23, pp. 134-148, 2011.

[22] G. Siemens and R. S. Baker, "Learning analytics and educational data mining: towards communication and collaboration," In 2012 proceedings of the 2nd international conference on learning analytics and knowledge, pp. 252-254.

[23] R. Ferguson and S. B. Shum, "Social learning analytics: five approaches," In 2012 proceedings of the 2nd International Conference on Learning Analytics and Knowledge, pp. 23-33.

[24] A. Bakharia, E. Heathcote, E., and S. Dawson, "Social networks adapting pedagogical practice: SNAPP," In: Same Places, Different Spaces. Ascilite 2009.

[25] J. Preece, and D. Maloney-Krichmar, "Online Communities". In J. Jacko and A. Sears, A. (Eds.) Handbook of Human-Computer Interaction, Lawrence Erlbaum Associates Inc. Publishers. Mahwah: NJ. pp. 596-620, 2003.

[26] M. Schlager, J. Fusco, and P. Schank, "Evolution of an online education community of practice". In K. A. Renninger and W. Shumar (Eds.), Building virtual communities: Learning and change in cyberspace, New York: Cambridge University Press, pp. 129-158, 2002.

[27] R. Farzan, J. M. DiMicco, and B. Brownholtz, "Spreading the honey: a system for maintaining an online community," In 2009 proceedings of the ACM 2009 international conference on Supporting group work, pp. $31-40$.

[28] F. Ortega, J. M. Gonzalez-Barahona, and G. Robles, "On the inequality of contributions to Wikipedia". In 2008 proceedings of the $41^{\text {st }}$ Hawaii International Conference on System Sciences, pp. 304-304.

[29] X. Ochoa and E. Duval, "Quantitative analysis of user-generated content on the Web," In 2008 Proceedings of webevolve2008: web science workshop at WWW2008, pp. 1-8.

[30] M. Feldman and J. Chuang, "Overcoming free-riding behavior in peerto-peer systems," ACM SIGecom Exchanges, vol. 5, no. 4, pp. 41-50, 2005.

[31] L. Ramaswamy and L. Liu, "Free riding: A new challenge to peer-topeer file sharing systems". In 2003 proceedings of the 36th Annual Hawaii International Conference on system sciences, pp. 10-20.

[32] M. Recker, J. Dorward, D. Dawson, S. Halioris, Y. Liu, X. Mao, ... and J. Park, "You can lead a horse to water: teacher development and use of digital library resources". In 2005 Proceedings of the Joint Conference on Digital Libraries, pp. 1-7.

[33] B. Xu and M. Recker, "Peer Production of Online Learning Resources: A Social Network Analysis," In 2010 Baker, R., Merceron, A., Pavlik, P.I. Jr. (Eds.). Proceedings of the 3rd International Conference on Educational Data Mining, pp. 315-316.

[34] H. Leary, S. Giersch, A. Walker, and M. Recker, "Developing a Review Rubric for Learning Resources in Digital Libraries," In 2009 Proceedings of the Joint Conference on Digital Libraries, pp. 421-422.
[35] L. Sellers, L. Ye, B. Robertshaw, M. Recker, and A. Walker, "Technology Integrated Professional Development: A Case Study of Junior High Science and Mathematics Teachers," presented at the Annual Meeting of the Associationfor Educational Communications Technology, Jacksonville, FL, Nov, 2011.

[36] A. Walker, M. Recker, B. Robertshaw, J.Olsen, L. Sellers, H. Leary, Y. Kuo, and L. Ye, "Designing For Problem Based Learning: A Comparative Study Of Technology Professional Development," presented at the Annual Meeting of the American Education Research Association, New Orleans, LA, Apr, 2011.

Min Yuan is currently pursuing her Ph.D from Utah State University, Logan, UT. Min got her bachelor's and master's degree from Nanjing Normal University, China. After that, she worked for four years at Yingtian College in China, and then started her Ph.D study at Utah State in 2011. Her research interests include teachers' evaluation of online resources, and online communities. She has several research papers in reputed international journal and conference.

Mimi Recker is Professor and Head of the Department of Instructional Technology \& Learning Sciences, Utah State University, Logan, Utah. Mimi has a bachelor's degree in mathematics from the University of Pennsylvania. After a few years as a software engineer in Silicon Valley, she earned her PhD from the University of California, Berkeley. Mimi worked for two years at the Georgia Institute of Technology, and four years at Victoria University in New Zealand, then came to Utah State in 1998. Her research focuses on helping the education sector reap the benefits of cyber-learning. Her goals are to help provide teachers and learners with access to a network of high-quality, interactive and free online learning resources. Her research, largely funded by the National Science Foundation, has involved collaborations with a dynamic mix of faculty, post-doctoral students, and graduate students from Utah State University, as well as colleagues from around the world. 